\title{
Acute Serotonin and Dopamine Depletion Improves Attentional Control: Findings from the Stroop Task
}

\author{
Kirsty E Scholes ${ }^{1,2,3}$, Ben J Harrison ${ }^{4}$, Barry V O'Neill ${ }^{1,2}$, Sumie Leung ${ }^{1,2}$, Rodney J Croft ${ }^{1,2}$, \\ Andrew Pipingas', K Luan Phan ${ }^{1,5}$ and Pradeep J Nathan*, \\ 'Behavioural Neuroscience Laboratory (BNL), Department of Physiology, Monash Centre for Brain and Behavior, Monash University, Melbourne, \\ VIC, Australia; ${ }^{2}$ Brain Sciences Institute, Swinburne University of Technology, Melbourne, VIC, Australia; ${ }^{3}$ Centre for Clinical Research in \\ Neuropsychiatry, School of Medicine and Pharmacology, University of Western Australia, Perth, WA, Australia; ${ }^{4}$ Melbourne Neuropsychiatry \\ Centre (MNC), Department of Psychiatry, The University of Melbourne, Melbourne, VIC, Australia; ${ }^{5}$ Clinical Neuroscience \& Psychopharmacology \\ Research Unit (CNPRU), Department of Psychiatry, The University of Chicago, Chicago, IL, USA
}

Schizophrenia is associated with impairments of attentional control on classic experimental paradigms such as the Stroop task. However, at a basic level the neurochemical mechanisms that may be responsible for such impairments are poorly understood. In this study, we sought to investigate the influence of brain monoamine function on Stroop task performance in healthy participants using the established methods of acute dietary serotonin, dopamine, and combined monoamine depletion. The study was a double-blind placebo controlled design in which 12 healthy male participants completed the Stroop task under four acute treatment conditions: (a) balanced/placebo control, (b) acute tryptophan depletion, (c) acute tyrosine/phenylalanine depletion, and (d) acute tyrosine/phenylalanine/tryptophan depletion (combined monoamine depletion). Decreased Stroop interference indicating improved attentional control was observed after both tryptophan depletion and tyrosine/phenylalanine depletion, while there was no significant change in interference after combined monoamine depletion. Findings suggest that reduced tonic dopamine or serotonin activity within specific neural circuits (such as the striatum, anterior cingulate, or prefrontal cortex) may play a critical role in attentional control, possibly by improving gating of information via reducing noise in monoaminergic systems. These findings enhance our understanding of the neurochemical basis of attentional control and the possible cause of attentional control deficits in schizophrenia.

Neuropsychopharmacology (2007) 32, 1600-1610; doi:I0.1038/sj.npp. I30 I262; published online 6 December 2006

Keywords: Stroop; dopamine; serotonin; attentional control; schizophrenia; amino acid depletion

\section{INTRODUCTION}

Schizophrenia is a severe, chronic and disabling psychiatric disorder prevalent in approximately $0.4-1 \%$ of the world's population (Bhugra, 2005; Jablensky, 2000). In addition to the positive and negative symptoms, patients also often experience severe disturbances in cognitive functioning (Abi-Dargham, 2004; Gold and Weinberger, 1995; Keefe et al, 2006). It has been suggested that cognitive deficits are the most 'functionally limiting' symptom dimension, and have the greatest impact on illness outcome in schizophrenia (Green, 1996; Green et al, 2000). With this recognition of cognitive impairment as a separable and unequi-

*Correspondence: Professor PJ Nathan, Behavioural Neuroscience Laboratory, Department of Physiology, Monash Centre for Brain and Behavior, Monash University, PO Box I3F, Clayton, VIC, 3800, Australia, Tel: 6 I 39905 2553, Fax: 6139905 2547,

E-mail: pradeep.nathan@med.monash.edu.au

Received 16 June 2006; revised 18 September 2006; accepted 5 October 2006 vocal feature in schizophrenia, basic research into the neurochemical basis of this phenomena, and the development of treatments that more effectively target cognition in schizophrenia, has become an area of rapidly growing interest (Carter, 2005).

One of the most prominent cognitive deficits in schizophrenia involves patients impaired ability to flexibly adjust attention and to inhibit or control irrelevant or unwanted responses in cognitive tasks (Andreasen, 1994; Barch et al, 2004; Kuperberg and Heckers, 2000). Experimentally, this deficit is most evident when patients are administered paradigms such as the Stroop Color-Word Interference task (Barch and Carter, 2005; Barch et al, 1999a, b, 2004; Braver et al, 1999; Carter et al, 1992; Chen et al, 2001; Cohen et al, 1990; Henik and Salo, 2004). The Stroop task is a wellestablished measure of attentional control and response inhibition, in which participants are presented with words printed in different ink colors and are told to name the print color and to ignore the stimulus word. In the singletrial version of the Stroop task, stimuli are presented on a computer screen one at a time, and participants are 
required to name the ink color of the individual stimulus (Henik and Salo, 2004; MacLeod, 1991). When the word and the ink color conflict, that is they are incongruent, participants are slower to respond than when there is no (or less) conflict, such as on neutral or congruent trials (Stroop, 1935). This reaction time difference is referred to as Stroop interference and shows high reproducibility and robustness within and across individuals (MacLeod, 1991). In contrast, a less studied phenomenon, referred to as Stroop facilitation, occurs when participants are faster to respond to stimuli when the color is congruent with the semantic meaning of the word, than to neutral stimuli such as patches of color (Barch et al, 1999a). However, facilitation is considered to be a somewhat weaker phenomenon than interference (MacLeod, 1991). Research suggests that patients with schizophrenia exhibit increased facilitation, an increased number of errors and increased reaction times to all stimuli, but have no difference in interference, when compared to healthy control participants on the single-trial version of the Stroop task (Barch et al, 1999a, b, 2004; Carter et al, 1992; Chen et al, 2001; Henik et al, 2002; Nordahl et al, 2001; Perlstein et al, 1998; Taylor et al, 1996). These findings are thought to be as a result of a specific failure in contextual processing, whereby patients have difficulty implementing and/or maintaining a representation of the task goals over time (Barch and Carter, 2005; Barch et al, 1999a, b). It should be noted that the pattern of deficits observed in schizophrenic patients when using an alternate Stroop procedure (the blocked card version) is somewhat different to those observed when using the single-trial version, and this is suggested to be due to the slightly different processes inherent in these different tasks (see Henik and Salo (2004)).

While these deficits of attentional control in the Stroop task have been well characterized in schizophrenia, and have been theoretically linked to abnormalities in dopamine function (Braver et al, 1999; Cohen et al, 2002), the underlying relationships between neurochemistry and attentional control are yet to be fully determined. Although it has been extensively hypothesized that both dopamine (Abi-Dargham, 2004; Andreasen, 1994; Laurelle, 1998, 1999) and serotonin (Abi-Dargham et al, 1997; Kapur and Remington, 1996) play a critical role in the neurochemical underpinnings of schizophrenia and the action of antipsychotic drugs, the exact role of dopamine and serotonin on Stroop performance and attentional control is not fully characterized. It has been suggested that both dopamine and serotonin may be involved in the disturbances to attentional control observed in patients with schizophrenia (Cohen and Servan-Schreiber, 1992; Kivircik Akdede et al, 2005), although many of the findings are confounded by medication use and institutionalization of patients, making it difficult to know whether reported deficits are trait related, or are secondary to other factors. Therefore, in order to try and understand the role of dopamine and serotonin on attentional control, many researchers have attempted to modulate these neurotransmitter systems using pharmacological probes in healthy participants to then make inferences about the possible influence of these neurotransmitters on attentional control in schizophrenia.

A number of studies have used acute tryptophan depletion (ATD) to examine the role of serotonin on Stroop performance. This technique acutely depletes serotonin and its metabolites in humans (Carpenter et al, 1998; Nishizawa et al, 1997; Williams et al, 1999), and has been shown to consistently impair serotonin dependant processes such as memory consolidation and learning (Harrison et al, 2004; Riedel et al, 2002; Schmitt et al, 2000). To date, the studies examining the effects of ATD on Stroop task performance have been somewhat inconsistent. While some studies have reported improved performance (ie, decreased interference) after ATD (Evers et al, 2006; Rowley et al, 1997; Schmitt et al, 2000), other studies have found no effects (Gallagher et al, 2003; Horacek et al, 2005; Sobczak et al, 2002). Similarly, studies examining the role of dopamine on Stroop performance (using dopamine agonists) have also yielded inconsistent results. For example, stimulation of dopamine $\mathrm{D}_{2}$ receptors using bromocriptine decreased Stroop interference (Roesch-Ely et al, 2005), while increasing synaptic dopamine with the indirect dopamine agonist, amphetamine, had no effect (Barch and Carter, 2005). Both studies, however, found no effects of dopaminergic modulation on Stroop facilitation, while the latter study also found improved reaction times to all stimuli (Barch and Carter, 2005). These conflicting findings may be due to factors such as the use of different pharmacological probes, as well as variability in the Stroop task methods used.

Therefore, to further explore the role of serotonin and dopamine on attentional control, we examined the effects of tryptophan (ie, serotonin) depletion and an analogous method of tyrosine/phenylalanine depletion (to deplete dopamine) on Stroop interference and facilitation. Acute tyrosine/phenylalanine depletion (ATPD) is a technique which has been shown to selectively decrease dopamine synthesis and release (Jaskiw and Bongiovanni, 2004; Leyton et al, 2004; McTavish et al, 1999a, 2001a, b; Mehta et al, 2005; Montgomery et al, 2003) and impair dopamine dependent cognitive processes such as working memory (Harmer et al, 2001; Harrison et al, 2004). To our knowledge, ATPD has never been used to investigate the effects of dopaminergic modulation on Stroop task performance. In addition, we also examined for the first time, the effects of simultaneous serotonin and dopamine depletion (ie, combined monoamine depletion) on Stroop interference and facilitation, using a method that was recently shown to simultaneously deplete tyrosine, phenylalanine, and tryptophan to levels that are expected to modulate central dopaminergic and serotonergic function (Nathan et al, 2004), and was subsequently shown to impair vigilance (Matrenza et al, 2004). Given the highly inconsistent findings concerning the direction of changes in Stroop performance associated with these depletion techniques, no specific predictions were made. However, in line with previous findings, it was predicted that both dopamine depletion and serotonin depletion would alter Stroop interference, but would have no effect on Stroop facilitation.

\section{MATERIALS AND METHODS}

\section{Participants}

The current study comprised 12 healthy nonsmoking male participants, aged $21-38$ years $(\mathrm{M}=25.83$ years, $\mathrm{SD}=4.67$ years). Participants were recruited for the study through 
university advertisements, and were considered for inclusion if they were not currently taking any medications, had no personal or family history of psychiatric disorders, had no history of substance abuse, and had no history of head injury. All participants underwent a medical examination by a registered physician prior to participation, in order to verify that they were physically and psychiatrically healthy and that they satisfied the inclusion criteria. Furthermore, all participants gave written informed consent for participation in the study, which was approved by the Swinburne University Human Research Ethics Committee.

\section{Study Design}

We used a double-blind, placebo controlled, repeated measures design in which each participant was tested under four acute treatment condition; (a) $100 \mathrm{~g}$ nutritionally balanced placebo control treatment (BAL), (b) acute tryptophan depletion treatment (ATD) (ie, serotonin depletion), (c) acute tyrosine and phenylalanine depletion treatment (ATPD) (ie, dopamine depletion), and (d) acute tyrosine, tryptophan, and phenylalanine depletion treatment (ie, combined monoamine depletion, CMD). Individual assignment to the order of completion of each treatment was randomized and counterbalanced using a computerized randomization program. Completion of each treatment was separated by a minimum 7-day washout period.

\section{Amino-Acid Composition}

The amino-acid composition for the depletion treatments were based on the $104 \mathrm{~g}$ balanced mixture developed by Young et al (1985) and Nathan et al (2004). In the current study, the balanced placebo control mixture consisted of $5.5 \mathrm{~g}$ of L-alanine, $3.2 \mathrm{~g}$ of glycine, $3.2 \mathrm{~g}$ of L-histidine, $8.0 \mathrm{~g}$ of L-isoleucine, $13.5 \mathrm{~g}$ of leucine, $11.0 \mathrm{~g}$ of L-lysine monohydrochloride, $5.7 \mathrm{~g}$ of L-phenylalanine, $12.2 \mathrm{~g}$ of L-proline, $6.9 \mathrm{~g}$ of L-serine, $6.5 \mathrm{~g}$ of L-threonine, $2.3 \mathrm{~g}$ of L-tryptophan, $6.9 \mathrm{~g}$ of L-tyrosine and $8.9 \mathrm{~g}$ of L-valine. L-Arginine $(4.9 \mathrm{~g})$, L-cysteine $(2.7 \mathrm{~g})$, and L-methionine $(3.0 \mathrm{~g})$ were encapsulated in 22 gelatin capsules and were administered separately due to their unpleasant taste. All treatment mixtures differed from the composition of the BAL mixture only in that, the mixture was deficient of L-tryptophan in the ATD treatment, the mixture was deficient of L-tyrosine and L-phenylalanine in the ATPD treatment, and in the CMD treatment the mixture was deficient of L-tryptophan, L-tyrosine, and L-phenylalanine.

\section{Procedure}

On the day before each testing session, participants were required to adhere to a low-protein diet, with their total protein consumption to be $<20 \mathrm{~g}$ (Young et al, 1985). In addition, participants were also required to fast from $1900 \mathrm{~h}$ that evening (with the exception of the consumption of water). This procedure has been employed in many previous studies as it has been suggested that it may enhance the effect of monoamine depletion and lessen the variability in baseline monoamine levels (Bel and Artigas, 1996; Bell et al, 2001; Harrison et al, 2004; Hood et al, 2005; Reilly et al, 1997). On arrival for testing, participants were required to complete the Visual Analog Mood Scales (VAMS) and then had a small sample of blood taken $(12 \mathrm{ml})$ to establish baseline mood and amino-acid levels, respectively. Participants were then administered the amino-acid drink and capsules. The powdered amino acids were mixed with $180 \mathrm{ml}$ of orange juice a few minutes prior to oral administration. Participants consumed the 22 capsules and then swallowed the amino-acid suspension immediately after. The participants were advised to drink this as quickly as possible given the unfamiliar and unpleasant taste. Upon completion of ingestion of the amino acids, participants were provided with sugar free chewing gum and a glass of water to cleanse the mouth. The process of amino-acid administration took approximately $10 \mathrm{~min}$.

To enable the depletion effects to occur, participants rested for the following $4 \mathrm{~h}$. During this time, they were allowed to consume water freely, but were restricted from any physical activity. At $2 \mathrm{~h}$ post-amino-acid administration, participants were provided with a low-protein snack of carrots and apples. At $4 \mathrm{~h}$ post-ingestion participants completed the Stroop task, which took approximately $10 \mathrm{~min}$. This $4 \mathrm{~h}$ latency period for testing was chosen to coincide with the timing of maximal monoamine depletion determined in previous research detailing the time course of monoamine depletion in rats (Bel and Artigas, 1996; McTavish et al, 1999b), human plasma (McTavish et al, 1999b; Moja et al, 1996; Sheehan et al, 1996), and cerebrospinal fluid (Carpenter et al, 1998; Williams et al, 1999). Following completion of the Stroop task, participants were again administered the VAMS to examine mood changes following treatment, and were required to give another sample of blood $(12 \mathrm{ml})$ in order to establish the levels of amino-acid depletion achieved. This was followed by further testing (electrophysiological recording) which will not be discussed in this study. Upon conclusion of the testing procedure, participants were provided with highprotein snacks in order to replenish their amino-acid levels. Participants resumed their normal diet between each of the testing sessions.

\section{Stroop Task}

Following the task used by Barch et al (1999a), we used a single trial version of the Stroop task consisting of 96 trials; with $24(25 \%)$ congruent trials, $24(25 \%)$ incongruent trials, and $48(50 \%)$ neutral trials. Each trial consisted of a stimulus printed in one of four colors: red, green, blue, or purple. The congruent stimuli consisted of each of the four color names printed in its own color (eg, the word red printed in red ink). The incongruent stimuli comprised each of the four color words printed in one of the three remaining colors (eg, the word red printed in blue ink). The neutral stimuli consisted of four color unrelated words (dog, bear, tiger, and monkey) presented in one of the four colors. These neutral words were from a single semantic category in order to eliminate semantic confounds (MacLeod, 1991), and matched the response set color words in terms of number of letters and frequency of occurrence in the English language (Francis and Kucera, 1982). The use of these animal words as the neutral stimuli, rather than patches of color, was due to previous research suggesting 
that these neutral stimuli are more likely to produce a Stroop facilitation effect in healthy participants (Barch and Carter, 2005; Barch et al, 1999a, 2004).

In each testing session, participants were seated $60 \mathrm{~cm}$ from a computer screen and told that they would view a series of stimuli one at a time, and that their task was to name the color in which the stimulus was printed as quickly and accurately as possible (Barch et al, 1999a). Each stimulus was presented on the screen for $2000 \mathrm{~ms}$, and was then replaced by a fixation cross for $2000 \mathrm{~ms}$. Regardless of the participant's reaction time to respond, a new trial began $4000 \mathrm{~ms}$ after the onset of the previous stimulus. This presentation was employed to ensure the task proceeded at a fixed pace for all participants (Barch et al, 1999a). Presentation of the stimuli was in a pseudo-random order. Participants were required to wear a headset with an attached microphone that recorded, and relayed to the computer, the reaction time for onset of the verbal responses. The verbal responses were monitored for accuracy (with the recording of errors in the naming of ink color) by the experimenter. To reduce any practice effects, each participant also completed a short practice version of the task (consisting of 25 stimuli) on two occasions before testing on the day of the first treatment session. Furthermore the order of treatment administration was randomized to further minimize practice effects, such that three participants received the order $A B C D$, three received the order $B A D C$, three received the order $C D A B$, and three received the order DCBA.

\section{Subjective Mood Assessment}

Subjective mood ratings were obtained using the Visual Analog Mood Scales (Bond and Lader, 1974). The VAMS consists of 16 bipolar scales, anchored at each end of a $100 \mathrm{~mm}$ line. In factor analyses these scales reduce to three subscales: alertness (nine items), contentedness (five items), and calmness (two items).

\section{Biochemical Analysis}

The venous blood samples $(12 \mathrm{ml})$ were separated by centrifugation for $20 \mathrm{~min}$ at 3000 r.p.m. within a few minutes of collection. Plasma was then yielded from the centrifuged samples and stored at $-20^{\circ} \mathrm{C}$. Concentrations of free amino acids tryptophan (TRYP), tyrosine (TYR), phenylalanine (PHE), valine (VAL), leucine (LEU), and isoleucine (ILE) in plasma were determined using precolumn derivatization with 6-aminoquinolyl- $N$-hydroxysuccinimidyl carbamate (AQC) followed by separation of the derivatives and quantification by reversed phase high-performance liquid chromatography (RP-HPLC) (Cohen, 2001). All amino acids except TRP were detected by fluorescence, while TRP required UV detection. VAL, LEU, and ILE levels were analyzed to calculate the ratio of plasma TRYP, TYR, or PHE, to other large neutral amino acids (LNAAs).

Prior to derivatization, the plasma samples $(100 \mu \mathrm{l})$ were diluted 1:1 with internal standard solution and deproteinized by ultrafilration through a membrane with a $10 \mathrm{kDa}$ nominal molecular weight cutoff (ultrafree MC with PL-10 membrane, Millipore, MA, USA). The filtrate $(100 \mu \mathrm{l})$ was then subjected to AQC derivatization and HPLC analysis using the Waters AccTag amino-acid analysis system (Waters Corporation, MA, USA) (Cohen, 2001).

\section{Statistical Analysis}

Owing to the presence of a number of deviations from the normal distribution, and skewed variables within the biochemical data (which were unaltered with application of transformations), the biochemical data was analyzed with nonparametric Friedman's tests. Significant results were followed-up with the Wilcoxon Signed Ranks Test. To investigate whether the Stroop task used in the present study was able to elicit interference and facilitation effects, a one-way repeated measures ANOVA, with stimulus RT (neutral, congruent, and incongruent) as the within subjects variable, was conducted on the data from the balanced placebo control treatment only. Stroop interference (mean incongruent RT - mean neutral RT) and facilitation (mean neutral RT - mean congruent RT) were computed for each participant. Computed scores for interference and facilitation, as well as reaction times to the three types of stimuli, were all analyzed with separate one-way repeated measures ANOVA's, with treatment as the within subjects variable. As there was almost no variability concerning errors made during the task (ie, most participants committed no errors), analysis of the error data was excluded. In order to test for any relationship between level of amino-acid depletion and Stroop performance, Pearson $r$ and Spearman rho correlational analyses were conducted. For each depletion treatment, percentage depletion ((post-level-pre-level)/prelevel ${ }^{\star} 100$ ) of each amino acid (TRYP, TYR, and PHE) was correlated with interference and facilitation scores for that treatment. VAMS data was analyzed using a four (treatment: BAL, ATD, ATPD, CMD) by three (subscale: alertness, contentedness, calmness) by two (time: baseline, posttreatment) repeated measures ANOVA.

\section{RESULTS}

\section{Amino-Acid Concentrations}

Friedman's test showed a significant effect of treatment on the plasma levels of the amino acids (TRYP, TYR, PHE) $\left(\chi^{2}(23)=148.41, p<0.001\right)$. Wilcoxon Signed Ranks tests (with significance set at $p<0.05$ ) demonstrated that, when compared to baseline concentrations of amino acids, there were significant increases in TRYP, TYR and PHE after the BAL treatment, and significant decreases in these amino acids after the CMD depletion treatment. After the ATD treatment there was a significant decrease in concentrations of TRYP, and no significant change in concentrations of TYR, when compared to baseline levels. After the ATPD treatment there was a significant increase in TRYP levels, as well as significant decreases in TYR and PHE levels, when compared to baseline concentrations. For percentages see Table 1.

A separate Friedman's test also revealed a significant effect of treatment on the amino acid ratios $\left(\chi^{2}(23)=\right.$ 138.06, $p<0.001$ ). Wilcoxon Signed Ranks Test (with significance set at $p<0.05$ ) indicated that after the BAL treatment there was a significant decrease in the ratio of TYR: $\sum$ LNAAs, but no significant change in the ratios of 
Table I Plasma Concentrations of Amino Acids ( $\mu \mathrm{mol} / \mathrm{l}$ ) (Mean (SD))

\begin{tabular}{|c|c|c|c|c|}
\hline Amino acid & $\begin{array}{l}\text { Treatment } \\
\text { condition }\end{array}$ & Baseline & $\begin{array}{l}4 \mathrm{~h} \text { post- } \\
\text { treatment }\end{array}$ & $\begin{array}{l}\text { Percent } \\
\text { change }\end{array}$ \\
\hline \multirow{4}{*}{$\begin{array}{l}\text { Plasma free } \\
\text { TRYP }\end{array}$} & BAL & $4.53(1.88)$ & I0.94 (3.42) & |41.50*** \\
\hline & CMD & $4.30(1.68)$ & $1.37(0.52)$ & -68.14 ** \\
\hline & ATD & $5.10(1.61)$ & $0.80(0.23)$ & $-84.3 \mid$ |** \\
\hline & ATPD & $4.23(1.92)$ & I5.07 (7.78) & 256.26 *** \\
\hline \multirow[t]{4}{*}{ Plasma TYR } & $\mathrm{BAL}$ & $49.06(11.35)$ & 97.41 (27.26) & 98.55**⿻丷木 \\
\hline & CMD & $47.33(10.83)$ & $10.60(3.33)$ & -77.60 *** \\
\hline & ATD & $65.49(46.78)$ & 96.74 (36.59) & 47.72 \\
\hline & ATPD & $46.73(14.02)$ & $12.93(4.42)$ & -72.33 ** \\
\hline \multirow[t]{4}{*}{ Plasma PHE } & BAL & $44.96(9.31)$ & $101.74(43.86)$ & 126.29** \\
\hline & CMD & $43.90(8.77)$ & $8.04(3.12)$ & $-81.69 * *$ \\
\hline & ATD & $50.3 \mid(|4.5|)$ & I 4.37 (52.31) & 127.33* \\
\hline & ATPD & $41.76(9.22)$ & $7.77(1.76)$ & $-81.39 * *$ \\
\hline \multirow{4}{*}{$\begin{array}{l}\text { TRYPI } \\
\sum L N A A s\end{array}$} & BAL & $0.015(0.006)$ & $0.012(0.003)$ & -20.00 \\
\hline & CMD & $0.015(0.005)$ & $0.002(0.001)$ & $-86.67 * *$ \\
\hline & ATD & $0.015(0.005)$ & 0.001 (0.00I) & $-93.33 * *$ \\
\hline & ATPD & $0.014(0.008)$ & $0.016(0.006)$ & 14.29 \\
\hline \multirow[t]{4}{*}{ TYR/ $\sum L N A A s$} & BAL & $0.162(0.031)$ & $0.109(0.024)$ & $-32.72 * *$ \\
\hline & CMD & $0.161(0.033)$ & $0.015(0.005)$ & $-90.68 * *$ \\
\hline & ATD & $0.162(0.030)$ & $0.131(0.060)$ & -19.14 \\
\hline & ATPD & $0.149(0.059)$ & $0.015(0.005)$ & $-89.93 * *$ \\
\hline \multirow[t]{4}{*}{$\mathrm{PHE} / \sum \mathrm{LNAAs}$} & BAL & $0.149(0.022)$ & $0.111(0.033)$ & -25.50 \\
\hline & CMD & $0.149(0.023)$ & $0.011(0.004)$ & $-92.62 * *$ \\
\hline & ATD & $0.142(0.034)$ & $0.140(0.034)$ & $-|.4|$ \\
\hline & ATPD & $0.134(0.027)$ & $0.009(0.003)$ & -93.28 ** \\
\hline
\end{tabular}

*p $<0.05$, *** $p<0.02$ (Post treatment compared to baseline).

BAL, balanced condition; CMD, combined monoamine depletion condition; ATD, acute tryptophan depletion condition; ATPD, acute tyrosine/phenylalanine depletion condition.

TRYP: $\sum L N A A$ or PHE: $\sum$ LNAAs, when compared to baseline amino acid ratios. There was a significant reduction from baselines in all amino acid ratios, after the CMD treatment. There were no significant decreases in the ratio of TYR: $\sum$ LNAAs or PHE: $\sum$ LNAAs after ATD; however, there was a significant reduction in the ratio of TRYP: ¿LNAAs, when compared to baseline. Lastly, after the ATPD condition there were significant reductions in the ratio of TYR: $\sum L N A A s$ and PHE: $\sum L N A A s$; however, there was no significant change in the ratio of TRYP: $\sum$ LNAAs, when compared to baseline. For percentages see Table 1 .

In order to examine whether levels of amino-acid depletion achieved after the CMD treatment were as large as in the ATD and ATPD treatments, percentage change of the amino acid ratio ((post-pre/pre) $\left.{ }^{*} 100\right)$ were compared across the treatment conditions. Wilcoxon Signed Ranks test (with significance set at $p<0.05$ ) revealed no significant difference in percentage change in the ratios of TYR: ¿LNAAs or PHE: $\sum$ LNAAs between ATPD and CMD treatments. Similarly, there was no significant difference in the percentage change of the ratio of TRYP: $\sum$ LNAAs, between ATD and CMD treatments.

\section{Stroop Performance}

The one-way repeated measures ANOVA, with Greenhouse Geisser correction, of the stimulus reaction times in the balanced control treatment revealed a significant main effect of stimulus type $(\mathrm{F}(1.34,17.39)=14.27, p=0.001$, partial $\eta^{2}=0.52$ ). Simple planned contrasts revealed that this significant main effect of stimulus was due to the presence of a significant difference between reaction times to incongruent stimuli when compared to neutral stimuli (ie, Stroop interference) $(\mathrm{F}(1,13)=58.93, p<0.001$, partial $\left.\eta^{2}=0.82\right)$, but no significant difference between reaction times to congruent stimuli when compared to neutral stimuli (ie, Stroop facilitation) $(\mathrm{F}(1,13)=0.47, p=0.51$, observed power $=0.10)($ ie, Table 2). Whereas a significant facilitation effect was not observed in the present study, and results are consistent with observed differences being attributable to expected sampling variation, the power was such that a real, but small, effect may have gone undetected.

The one-way repeated measures ANOVA of the reaction times revealed no significant main effect of treatment on reaction times to incongruent stimuli $(\mathrm{F}(3,33)=1.18$, $p=0.33$, observed power $=0.29)$, reaction times to congruent stimuli $(\mathrm{F}(3,33)=1.16, p=0.34$, observed power $=$ $0.28)$ or reaction times to neutral stimuli $(\mathrm{F}(3,33)=1.18$, $p=0.33$, observed power $=0.29$ ).

The one-way repeated measures ANOVA of the interference scores revealed a significant main effect of treatment $\left(\mathrm{F}(3,33)=4.89, p=0.006\right.$, partial $\left.\eta^{2}=0.31\right)$, with simple planned contrasts revealing a no significant difference in interference under the CMD treatment when compared to the BAL treatment $(\mathrm{F}(1,11)=4.53, p=0.06$, observed power $=0.49$ ), and significant decreases in interference under both the ATD treatment $(\mathrm{F}(1,11)=10.53$, $p=0.01$, partial $\left.\eta^{2}=0.49\right)$ and the ATPD treatment $\left(\mathrm{F}(1,11)=7.39, p=0.02\right.$, partial $\left.\eta^{2}=0.40\right)$, when compared to the BAL condition. In contrast, the one-way ANOVA of the facilitation scores revealed no significant main effect of treatment $(\mathrm{F}(3,33)=0.31, p=0.82$, observed power $=$ 0.10) (Figure 1, Table 2).

\section{Correlations between Stroop Performance and Depletion Levels}

There were no significant correlations (Pearsons and Spearmans) between levels of depletion and Stroop performance under each treatment condition (all $p$ 's $>0.05$ ).

\section{Subjective Mood}

There were no significant changes in mood following any of the treatment conditions for VAMS subscales alertness, contentedness and calmness (all $p$ 's $>0.05$ ) (Table 3). 
Table 2 Means and Standard Deviations of Stroop Task Measures Under Each Treatment Condition (Mean (SD))

\begin{tabular}{|c|c|c|c|c|}
\hline & BAL condition & CMD condition & ATD condition & ATPD condition \\
\hline Neutral RT (ms) & $876.99(171.82)$ & $860.18(157.02)$ & $894.19(194.54)$ & $902.67(184.96)$ \\
\hline Incongruent RT (ms) & $960.47(161.16)$ & $915.88(164.78)$ & $922.63(179.73)$ & $932.20(171.03)$ \\
\hline Facilitation (neutral-congruent) & $10.68(24.61)$ & $25.01(14.07)$ & $29.09(19.63)$ & |3.35 (|8.5|) \\
\hline Interference (incongruent-neutral) & $83.48(9.97)$ & $55.69(7.32)$ & $28.44(|4.7|)^{*}$ & $29.53(14.63)^{*}$ \\
\hline
\end{tabular}

BAL, balanced control condition; CMD, combined monoamine depletion; ATD, acute tryptophan depletion; ATPD, acute tyrosine/phenylalanine depletion.

*Indicates significant differences between ATD or ATPD conditions in comparison to BAL condition $(p<0.05)$.

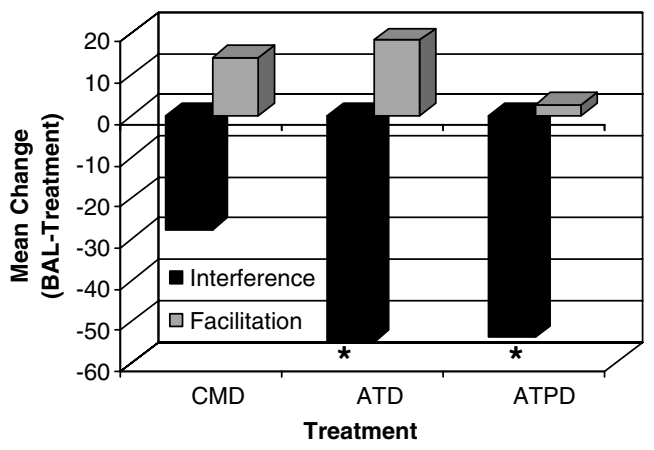

Figure I Mean change in interference and facilitation scores for each depletion treatment condition relative to the BAL treatment condition. *Indicates significant change in the ATD and ATPD treatments relative to $\mathrm{BAL}$ treatment; $p<0.05$. $\mathrm{BAL}=$ Balanced control condition, $\mathrm{CMD}=$ Combined monoamine depletion, ATD = Acute tryptophan depletion, ATPD $=$ Acute tyrosine/phenylalanine depletion.

\section{DISCUSSION}

The present study examined the effects of acute serotonin and dopamine depletion on performance of the Stroop task in healthy participants. In addition this study examined the effects of simultaneous serotonin and dopamine depletion on Stroop task performance. Improvements in Stroop performance, as measured by decreased interference, were observed after independent dopamine and serotonin depletion. Simultaneous depletion of both dopamine and serotonin produced a level of interference that was not significantly different from the balanced control, and was intermediate between the balanced control and the levels produced by individual depletions. These effects were observed independent of any effects on mood, consistent with growing evidence for lack of mood changes following amino-acid depletion methods in healthy subjects (see Harrison et al, 2002). Thus, our findings suggest an important role for dopamine and serotonin in the neurochemical basis of attentional control.

Acute tryptophan depletion resulted in a 93\% decrease in the ratio of tryptophan to other LNAA's (TRYP/LNAA), which is thought to be a more accurate indicator of brain serotonin concentrations than absolute plasma levels of tryptophan (Oldendorf and Szabo, 1976; Fernstrom et al, 1979). This decrease in TRYP/LNAA ratio is comparable to, and in fact exceeds that obtained in many studies (Schmitt et al, 2000; Leyton et al, 1999, 2000). Decreases of tryptophan of comparable magnitude have been shown to significantly affect central serotonin function, as evidenced by significant decreases in CSF concentration of serotonin metabolites (Carpenter et al, 1998; Williams et al, 1999), moderate decreases in brain serotonin synthesis (Moja et al, 1989; Nishizawa et al, 1997), and modulation of serotonindependent cognitive processes such as declarative episodic memory (Schmitt et al, 2000; Harrison et al, 2004). Following tryptophan depletion, we observed a significant reduction of Stroop interference, but no effects on Stroop facilitation or overall reaction times. The decrease in Stroop interference following tryptophan depletion indicates improved Stroop task performance, presumably through mechanisms of enhanced attentional control. Importantly, these effects were independent of speed of processing, as tryptophan depletion did not modulate overall reaction time performance. These findings are consistent with a number of studies which have also found decreased Stroop interference following tryptophan depletion (Evers et al, 2006; Schmitt et al, 2000). A relationship between serotonin and attentional control is also supported by studies in rats using the 5 choice serial reaction time task (5-CSRTT) in which enhanced premature responses (a measure of failure of behavioral inhibition) have been noted under conditions of increased serotonin neurotransmission (Dalley et al, 2002; Koskinen et al, 2003; Koskinen and Sirvio, 2001), particularly in the infralimbic/prelimbic regions of the medial prefrontal cortex (Dalley et al, 2002). Similarly, it has been found that increased serotonergic function can increase premature responses in a behavioral inhibition task in healthy humans (Del-Ben et al, 2005). Together these findings suggest that the serotonergic system within specific areas of the cortex may play an important role in attentional control, with reduced serotonergic transmission associated with greater attentional control or behavioral inhibition.

Interestingly, in a recent fMRI study (Evers et al, 2006), the effect of tryptophan depletion on Stroop interference was also associated with concurrent increased activation of the anterior cingulate and lateral prefrontal cortices, two brain regions thought to be critically involved in the performance of this task (eg, see Botvinick et al (2004)). It has been previously suggested that this improved performance may be due to the removal of the inhibitory actions of serotonin over cortical arousal (Schmitt et al, 2000). To this end, because serotonin appears to act to promote cortical de-arousal systems (Robbins, 1997), decreasing serotonergic function would reduce this inhibitory function thereby improving arousal and attention (Robbins, 1997). 
Table 3 Means and SD of VAMS Scores, Pre and Post Each Treatment Condition (Mean (SD))

\begin{tabular}{|c|c|c|c|c|c|}
\hline Subscale & Time of measurement & BAL condition & CMD condition & ATD condition & ATPD condition \\
\hline \multirow[t]{2}{*}{ Alertness } & Pre-treatment & $34.22(21.75)$ & $32.49(18.96)$ & $37.69(21.27)$ & $34.96(17.43)$ \\
\hline & Post-treatment & $38.83(20.35)$ & $45.09(19.06)$ & $39.85(23.03)$ & $42.39(22.06)$ \\
\hline \multirow[t]{2}{*}{ Contentedness } & Pre-treatment & $27.7 \mid(18.86)$ & $27.83(17.00)$ & $28.19(14.59)$ & $28.66(15.30)$ \\
\hline & Post-treatment & $27.44(13.02)$ & $30.81(14.27)$ & $31.05(13.14)$ & $33.06(\mid 5.31)$ \\
\hline \multirow[t]{2}{*}{ Calmness } & Pre-treatment & $23.46(14.93)$ & $23.79(14.62)$ & $28.82(19.43)$ & $28.29(18.72)$ \\
\hline & Post-treatment & $25.18(14.22)$ & $26.14(14.64)$ & $32.50(19.50)$ & $27.79(20.33)$ \\
\hline
\end{tabular}

BAL, balanced control treatment; CMD, combined monoamine depletion; ATD; acute tryptophan depletion; ATPD, acute tyrosine/phenylalanine depletion.

Furthermore, it has been shown that a close interaction exists between the serotonergic and noradrenergic systems, such that destruction or inhibition of serotonergic neurons results in an activation of noradrenergic neurons (McRaeDegueurce et al, 1985; Tian et al, 1993). Therefore, it is possible that acute tryptophan and serotonin depletion in the current study also resulted in indirect activation of noradrenergic function, leading to greater attentional control and improved Stroop task performance. In support, increasing noradrenergic function (via noradrenergic reuptake inhibition) has been shown to improve response inhibition in a stop signal task (Chamberlain et al, 2006).

Like ATD, acute tyrosine/phenylalanine depletion resulted in an $83 \%$ decrease in the ratio of tyrosine to other LNAA's (TYR/LNAA) and a 93\% decrease in the ratio of phenylalanine to other LNAA's (PHE/LNAA). These depletion levels were similar in magnitude to those observed in previous studies using the TYR/PHE depletion method (plasma TYR/PHE: $53-76 \%$ depletion; TYR/PHE to LNAA ratio: 99\% depletion) (Leyton et al, 1999, 2000; Harmer et al, 2001). Previous studies in animals with TYR depletion between 30 and $40 \%$, have shown significant reductions in catecholamine metabolites (Palmour et al, 1998) and catecholamine synthesis in the brain (Jaskiw and Bongiovanni, 2004; McTavish et al, 1999a). In humans, depletion of TYR/PHE to this magnitude has been shown to cause significant increases in plasma prolactin levels (an indirect measure of dopamine function) (Harmer et al, 2001; Harrison et al, 2004) and to impair dopamine dependent cognitive processes such as spatial working memory function (Harmer et al, 2001) due to reductions in 'tonic' dopamine. Depletion of dopamine with tyrosine/phenylalanine depletion in the present study also resulted in a decrease in Stroop interference, with no changes in Stroop facilitation or overall reaction times. The improved Stroop performance following dopamine depletion (like serotonin depletion) suggests greater attentional control, as these effects were observed independent of effects on general speed of information processing (ie, overall reaction time). These findings are somewhat contrary to the findings of Roesch-Ely et al (2005) who found decreased Stroop interference with stimulation of $\mathrm{D}_{2}$ receptors. These findings are also contrary to molecular imaging studies (ie, PET Imaging with $\left.\left[{ }^{18} \mathrm{~F}\right] \mathrm{FDOPA}\right)$ in which a negative association between regional $\left[{ }^{18} \mathrm{~F}\right]$ FDOPA uptake (a measure of dopamine synthesis) and Stroop interference has been found in normal control subjects and patients with Parkinson's disease and schizophrenia (Bruck et al, 2005, 2001; McGowan et al, 2004).

The inconsistency in the findings may be related to differences in the potency and specificity of the pharmacological probes used to manipulate dopamine function and consideration of the impact of global $v s$ regional changes in dopamine function on Stroop performance and attentional control. For instance, tyrosine/phenylalanine depletion is thought to affect global brain dopamine function via modulation of the synthesis and transport processes (Fadda, 2000; Oldendorf and Szabo, 1976; Reilly et al, 1997), while the method used by Roesch-Ely et al (2005), that is the administration of a dopamine $D_{2}$ receptor agonist, is thought to affect dopaminergic function through stimulation of $\mathrm{D}_{2}$ receptors specifically, at either cortical or striatal areas. Further, given that $\mathrm{D}_{2}$ receptors are found both pre- and post-synaptically on dopamine neurons in different agonist affinity states (Wolf and Roth, 1987), the resultant effect on dopamine neurotransmission may vary depending on the site of action and the dosage. Consistent with this proposal, and the findings of the current study, are observations from a number of studies in marmosets indicating differential effects of frontal $v s$ striatal dopamine depletion on cognitive processing (Crofts et al, 2001; Roberts et al, 1994). Whilst 6-OHDA lesions to the prefrontal cortex caused increased distractibility and impairment in maintenance of an attentional set (Crofts et al, 2001; Roberts et al, 1994), lesions of the striatum induced greater focusing on the relevant perceptual dimension during maintenance of an attentional set (Crofts et al, 2001). That is, marmosets with decreased striatal dopamine function were significantly more task engaged than control marmosets (Crofts et al, 2001). In addition, findings from the 5-CSRTT indicate that premature responding (or failure of behavioral inhibition) can be decreased in rats by the dopamine $\mathrm{D}_{2}$ receptor agonist quinpirole, which is thought to decrease dopaminergic neurotransmission by stimulating presynaptic dopamine $\mathrm{D}_{2}$ receptors (Passetti et al, 2003); while increasing dopamine neurotransmission with amphetamine and cocaine (Cole and Robbins, 1987; Harrison et al, 1997; van Gaalen et al, 2006) and with dopamine reuptake inhibitors (van Gaalen et al, 2006) increases premature responding, an effect that is suppressed with dopamine $D_{2}$ 
receptor antagonism (van Gaalen et al, 2006) and dopamine depletion (Cole and Robbins, 1987). Together, these findings suggest that the findings by Roesch-Ely et al (2005) of decreased Stroop interference (ie, improved attentional control) with stimulation of $\mathrm{D}_{2}$ receptors may reflect a presynaptic mechanism leading to decreased dopamine neurotransmission. This is also supported by the evidence that haloperidol ( $\mathrm{a}_{2}$ antagonist which inhibits post-synaptic dopamine transmission) has been shown to similarly reduce Stroop interference in healthy participants (Williams et al, 1996).

Our findings may also be consistent with the growing evidence that tasks which are associated with time constraints, or are dependent on processing within short durations, and those that rely on suppressing attention to competing information (such as the Stroop task), may be linked to dopaminergic modulation of the striatum (and basal ganglia) or fronto-striato-thalamic circuitry (for a review see Cropley et al, 2006). Therefore, it is possible that, consistent with McTavish et al (1999a), our findings relate to a predominant effect of tyrosine/phenylalanine depletion on dopamine function within the striatum. Indeed, recently Mehta et al (2005) demonstrated that tyrosine/phenylalanine depletion predominantly depleted dopamine in the striatum (indicated by an increase in $\mathrm{D}_{2}$ receptor binding measured with PET imaging using $\left[{ }^{11} \mathrm{C}\right]$ raclopride) and this was directly correlated with changes in cognitive function. Performance of the Stroop task appears to engage a widely distributed network of regions (Harrison et al, 2005), with studies consistently reporting activation of medial (ie, anterior cingulate cortex) and lateral prefrontal cortices (for a review see Neumann et al, 2005). Therefore, it is likely that changes in dopaminergic neurotransmission within specific neural circuits linked to attentional control (such as the striatum, anterior cingulate, or prefrontal cortex) may be more specifically linked to improved performance. The role of dopamine in attentional control is also consistent with the model of dopamine function and cognitive control suggested by Braver et al (1999). In this model, dopamine acts as a gating mechanism to prefrontal cortex attentional control, such that increased noise level in mesocortical dopamine induces deficits in maintenance and updating of context (which is critical for cognitive control). Such a disturbance was linked to both increased tonic and decreased phasic dopamine activity. Our findings of improved cognitive control following decreases in tonic dopamine, fits with such a model. Future studies investigating the relationship between Stroop performance, pharmacological probes for tonic (ie, dopamine depletion methods) and phasic dopamine (ie, amphetamine challenge) and PET imaging studies of dopamine function (ie, $\left[{ }^{18} \mathrm{~F}\right]$ FDOPA uptake in the striatum, cingulate, and prefrontal cortex) would further enhance our understanding of the relationship between dopamine function and neuroanatomical substrates of cognitive control.

Combined monoamine depletion with acute tyrosine/ phenylalanine/tryptophan depletion resulted in a $86 \%$ decrease in the ratio of tryptophan to other LNAA's, as well a $90 \%$ decrease in the ratio of tyrosine to other LNAA's, and a $92 \%$ decrease in the ratio of phenylalanine to other LNAA's. These decreases were not statistically different to those achieved with tryptophan depletion or tyrosine/ phenylalanine depletion alone, suggesting that all three monoamine precursors were simultaneously depleted to levels that are expected to affect central dopaminergic and serotonergic function (Nathan et al, 2004). However, simultaneous depletion of serotonin and dopamine did not result in significant changes in Stroop interference, Stroop facilitation or reaction times. An apparent nonsignificant improvement in Stroop interference was observed ( $p=0.057)$, however, the power was low in this comparison, most likely due to the small effect size. It is possible that this attenuated effect may have been due to a complex interaction between the serotonin and dopamine systems. Indeed, both systems have been shown to interact at a neuronal level, although the functional relevance of this interaction has not been fully determined (Costall et al, 1976; Jones et al, 1981; Parsons and Justice, 1993; Soubrie et al, 1984). It is possible that tryptophan depletion may result in the removal of serotonin's inhibitory influence on dopamine and noradrenaline neurotransmission (Gately et al, 1985; Lucki and Harvey, 1976; McRae-Degueurce et al, 1985; Segal, 1976; Tian et al, 1993), and this disinhibition is counteracted by simultaneous tyrosine depletion (impacting upon dopamine neurotransmission), thus resulting behaviorally in an attenuated effect on cognitive control.

In the current study, there was insufficient power to detect a small but real facilitation effect in the healthy participants, if it were there. Obviously this would have hindered our ability to detect any changes in Stroop facilitation under the different treatment conditions, although previous studies have also not found any changes in facilitation following dopaminergic or serotonergic modulation (Roesch-Ely et al, 2005; Schmitt et al, 2000). Despite this, future research may consider using faster stimulus presentation, or a larger sample size, in order to reproduce this phenomenon of facilitation (Barch et al, 2004), and to extend our observations. In addition, we also found no significant correlations between the level of tryptophan or tyrosine/phenylalanine depletion in plasma and Stroop performance. However, the extent to which changes in plasma precursor levels reflect corresponding changes in neurotransmitter concentrations in the brain remains unresolved. There is some evidence that peripheral precursor levels are poor correlates of central neurotransmitter levels and associated cognitive changes (Mehta et al, 2005), thus it is not all that surprising that they did not correlate with Stroop performance in the current study.

Given that the amino-acid depletion techniques are thought to alter global brain neurotransmitter function (Fadda, 2000; Oldendorf and Szabo, 1976); the current study was limited in that it could not directly test the hypotheses regarding the effects of region specific neurotransmitter disturbances in schizophrenia. Thus, such acute depletion techniques are not appropriate models of the hypothesized neurotransmitter disturbances in schizophrenia (such as cortical $v s$ striatal dopamine dysfunction). However, this study has aided our understanding of the effects of serotonin and dopamine modulation on Stroop performance, which in turn can be used to make future inferences about the possible causes of disturbances to Stroop task performance in schizophrenia. The findings of the current study suggest that decreases of overall dopamine or serotonin can improve attentional control, and thus treatments 
causing similar changes in dopamine and serotonin neurotransmission may be of use in ameliorating the disturbances to attentional control in schizophrenia. Furthermore, given that global depletion of serotonin and dopamine in the current study did not replicate the deficits observed in schizophrenia using the single-trial Stroop task, and the administration of amphetamine (which similarly causes global changes in dopamine neurotransmission) to patients with schizophrenia also did not abolish these specific deficits (Barch and Carter, 2005), it suggests that Stroop abnormalities in schizophrenia may be due to dopamine and serotonin dysfunction in specific pathways (ie, increased striatal dopamine). Furthermore, the findings suggest that the function of both neurotransmitters should be considered in future models of the neurochemical basis of Stroop task disturbances in schizophrenia.

In conclusion, the findings of the current study suggest that reduced tonic serotonin or dopamine, possibly in the frontal cortex and striatum respectively, may lead to improved attentional control, through greater focusing on the relevant perceptual dimension (ie, color naming). These findings go towards increasing out understanding of the neurochemical basis of attentional control, and highlight the necessity for basic neurochemical studies in healthy participants in order to improve our understanding of the nature of cognitive deficits in schizophrenia.

\section{ACKNOWLEDGEMENTS}

We acknowledge the contribution of Mr Alan Dunne, a PhD student from Ireland, who tragically passed away during the study. He will be sadly missed by all. We also thank Dr Susan Ilic for performing medicals on the study participants and for being on-call during the study. Biochemical assays were performed by Dr Bernie McInerney under the auspices of the Australian Proteome Analysis Facility established under the Australian Government's Major National Research Facilities program. Fellowship support for Professor Pradeep Nathan was provided by the National Health and Medical Research Council (NHMRC) of Australia (I.D. 345709). Dr Harrison is supported by a NHMRC Training Award (I.D. 400420).

\section{REFERENCES}

Abi-Dargham A (2004). Do we still believe in the dopamine hypothesis? New data bring new evidence. Int J Neuropsychopharmacol 7: S1-S5.

Abi-Dargham A, Laruelle M, Aghajanian GK, Charney D, Krystal J (1997). The role of serotonin in the pathophysiology and treatment of schizophrenia. J Neuropsychiatry Clin Neurosci 9: $1-17$.

Andreasen NC (1994). The mechanisms of schizophrenia. Curr Opin Neurobiol 3: 245-251.

Barch DM, Carter CS (2005). Amphetamine improves cognitive function in medicated individuals with schizophrenia and in healthy volunteers. Schizophr Res 77: 43-58.

Barch DM, Carter CS, Hachten C, Usher M, Cohen JD (1999a). The benefits of distractibility: mechanisms underlying increased stroop effects in schizophrenia. Schizophr Bull 25: 749-762.

Barch DM, Carter CS, Perlstein W, Baird J, Cohen JD, Schooler N (1999b). Increased Stroop facilitation effects in schizophrenia are not due to increased automatic spreading activation. Schizophr Res 39: 51-64.

Barch DM, Cohen JD, Carter CS (2004). Factors influencing Stroop performance in schizophrenia. Neuropsychology 18: 477-484.

Bel N, Artigas F (1996). Reduction in serotonergic function in rat brain by tryptophan depletion: effects in control and fluvoxamine-treated rats. J Neurochem 67: 669-675.

Bell B, Abrams J, Nutt D (2001). Tryptophan depletion and its implications for psychiatry. Br J Psychiatry 178: 399-405.

Bhugra D (2005). The global prevalence of schizophrenia. PLoS Med 2: e151.

Bond A, Lader M (1974). The use of analog scales in rating subjective feelings. Br J Med Psychol 47: 211-218.

Botvinick MM, Cohen JD, Carter CS (2004). Conflict monitoring and anterior cingulate cortex: An update. Trends Cogn Sci 8: 539-546.

Braver TS, Barch DM, Cohen JD (1999). Cognition and control in schizophrenia: a computational model of dopamine and prefrontal function. Biol Psychiatry 46: 312-328.

Bruck A, Aalto S, Nurmi E, Bergman J, Rinne JJ (2005). Cortical 6-fluoro-L-dopa uptake and frontal cognitive function in early Parkinsons disease. Neurobiol Aging 26: 891-898.

Bruck A, Portin R, Lindell A, Laihinen A, Bergman J, Haaparanta $M$ et al (2001). Positron emission tomography shows that impaired frontal lobe functioning in Parkinson's disease is related to dopaminergic hypofunction in the caudate nucleus. Neurosci Lett 311: 81-84.

Carpenter LL, Anderson GM, Pelton GH, Gaudin JA, Kirwin PDS, Price LH et al (1998). Tryptophan depletion during continuous CSF sampling in healthy human subjects. Neuropsychopharmacology 19: 26-35.

Carter CS (2005). Applying new approaches from cognitive neuroscience to enhance drug development for the treatment of impaired cognition in schizophrenia. Schizophr Bull 31: 810-815.

Carter CS, Robertson LC, Nordahl TE (1992). Abnormal processing of irrelevant information in chronic schizophrenia: Selective enhancement of Stroop facilitation. Psychiatry Res 41: 137-146.

Chamberlain SR, Muller U, Blackwell AD, Clarck L, Robbins TW, Sahakian BJ (2006). Neurochemical modulation of response inhibition and probabilistic learning in humans. Science 311: 861-863.

Chen EYH, Wong AWS, Chen RYL, Au JWY (2001). Stroop interference and facilitation effects in first-episode schizophrenic patients. Schizophr Res 48: 29-44.

Cohen JD, Braver TS, Brown JW (2002). Computational perspectives on dopamine function in the prefrontal cortex. Curr Opin Neurobiol 12: 223-229.

Cohen JD, McClelland JL, Dunbar K (1990). On the control of automatic processes: a parallel distributed processing account of the Stroop effect. Psychol Rev 97: 332-361.

Cohen JD, Servan-Schreiber D (1992). Context, cortex and dopamine: a connectionist approach to behaviour and biology in schizophrenia. Psychol Rev 99: 45-77.

Cohen SA (2001). Amino acid analysis using precolumn derivatisation with 6-aminoquino lyl- $N$-hydroxysuccinimidyl carbamate. In: Cooper C, Packer N, Williams K (eds). Methods in Molecular Biology. Humana Press: New Jersey. pp 39-47.

Cole BJ, Robbins TW (1987). Amphetamine impairs the discriminative performance of rats with dorsal noradrenergic bundle lesions on a 5-choice serial reaction time task: New evidence for central dopaminergic-noradrenergic interactions. Psychopharmacology (Berlin) 91: 458-466.

Costall B, Naylor RJ, Marsden CD, Pycock CJ (1976). Serotonergic modulation of the dopamine response from the nucleus accumbens. J Pharm Pharmacol 28: 523-526.

Crofts H, Dalley J, Collins P, Van Denderen J, Everitt B, Robbins T et al (2001). Differential effects of 6-OHDA lesions of the frontal 
cortex and caudate nucleus on the ability to acquire an attentional set. Cereb Cortex 11: 1015-1026.

Cropley VL, Fujita M, Innis RB, Nathan PJ (2006). Molecular imaging of the dopaminergic system and its association with human cognitive function. Biol Psychiatry 59: 1015-1026.

Dalley JW, Theobald DE, Pereira EA, Li PM, Robbins TW (2002). Specific abnormalities in serotonin release in the prefrontal cortex of isolation-reared rats measured during behavioural performance of a task assessing visuospatial attention and impulsivity. Psychopharmacology (Berlin) 164: 329-340.

Del-Ben CM, Deakin JFW, Mckie S, Delvai NA, Williams SR, Elliott $\mathrm{R}$ et al (2005). The effect of citalopram pretreatment on the neuronal responses to neuropsychological tasks in normal volunteers: an fMRI study. Neuropsychopharmacology 30: 1724-1734.

Evers EA, van der Veen FM, Jolles J, Deutz NE, Schmitt JA (2006). Acute tryptophan depletion improves performance and modulates the BOLD response during a Stroop task in healthy females. Neuroimage 32: 248-255.

Fadda F (2000). Tryptophan-free diets: a physiological tool to study brain serotonin function. News Physiol Sci 15: 260-264.

Fernstrom JD, Wurtman RJ, Hammarstrom-Wiklund B, Rand WM, Munro HN, Davidson CS (1979). Diurnal variations in plasma concentrations of tryptophan, tyrosine and other neutral amino acids: effects of dietary protein intake. Am J Clin Nutr 32: 1912-1922.

Francis WN, Kucera H (1982). Frequency Analysis of English Usage: Lexicon and Grammar. Houghton Mifflin: Boston.

Gallagher P, Massey AE, Young AH, McAllister-Williams RH (2003). Effects of acute tryptophan depletion on executive function in healthy young male volunteers. BMC Psychiatry 3: 1-9.

Gately PF, Poon SL, Segal DS, Geyer M (1985). Depletion of brain serotonin by 5,7-dihydroxytrytamine alters the response to amphetamine and the habituation of lovomotor activity in rats. Psychopharmacology (Berlin) 87: 400-405.

Gold JM, Weinberger DR (1995). Cognitive deficits and the neurobiology of schizophrenia. Curr Opin Neurobiol 5: 225-230.

Green MF (1996). What are the functional consequences of neurocognitive deficits in schizophrenia? Am J Psychiatry 153: 321-330.

Green MF, Kern RS, Braff DL, Mintz J (2000). Neurocognitive deficits and functional outcome in schizophrenia: Are we measuring the 'right stuff? Schizophr Bull 26: 119-136.

Harmer CJ, McTavish SF, Clark L, Goodwin GM, Cowen PJ (2001). Tyrosine depletion attenuates dopamine function in healthy volunteers. Psychopharmacology (Berlin) 151: 105-111.

Harrison AA, Everitt BJ, Robbins TW (1997). Central 5-HT depletion enhances impulsive responding without affecting the accuracy of attentional performance: interactions with dopaminergic mechanisms. Psychopharmacology (Berlin) 133: 329-342.

Harrison BJ, Olver J, Norman TR, Nathan PJ (2002). Effects of serotonin $v s$ catecholamine depletion on mood and IL-6 activation in human volunteers. Hum Psychopharmacol 17: 293-297.

Harrison BJ, Olver JS, Norman TR, Burrows GD, Wesnes KA, Nathan PJ (2004). Selective effects of acute serotonin and catecholamine depletion on memory in healthy women. J Psychopharmacol (Oxford) 18: 29-36.

Harrison BJ, Shaw M, Yucel M, Purcell R, Brewer WJ, Strother SC et al (2005). Functional connectivity during stroop task performance. Neuroimage 24: 181-191.

Henik A, Carter CS, Salo R, Chaderjian M, Kraft L, Nordahl TE et al (2002). Attentional control and word inhibition. Psychiatry Res 110: 137-149.

Henik A, Salo R (2004). Schizophrenia and the Stroop effect. Behav Cogn Neurosci Rev 3: 42-59.
Hood SD, Bell CJ, Nutt DJ (2005). Acute tryptophan depletion. Part 1: rationale and methodology. Aust NZ J Psychiatry 39: 558-564. Horacek J, Zavesicka L, Tintera J, Dockery C, Platilova V, Kopecek $\mathrm{M}$ et al (2005). The effect of tryptophan depletion on brain activation measured by functional magnetic resonance imaging during the Stroop test in healthy subjects. Physiol Res 54: 235-244.

Jablensky A (2000). Epidemiology of schizophrenia: the global burden of disease and disability. Eur Arch Psychiatry Clin Neurosci 250: 274-285.

Jaskiw GE, Bongiovanni R (2004). Brain tyrosine depletion attenuates haloperidol-induced striatal dopamine release in vivo and augments haloperidol-induced catelepsy in rats. Psychopharmacology (Berlin) 172: 100-107.

Jones DL, Mogenson GJ, Wu M (1981). Injections of dopaminergic, cholinergic, serotonergic and GABAergic drugs into the nucleus accumbens: effects on locomotor activity in the rat. Neuropharmacology 20: 29-37.

Kapur S, Remington G (1996). Serotonin-dopamine interaction and its relevance to schizophrenia. Am J Psychiatry 153: 466-476.

Keefe RS, Bilder R, Harvey PD, Davis SM, Palmer BW, Gold JM et al (2006). Baseline neurocognitive deficits in the CATIE schizophrenia trial. Neuropsychopharmacology 31: 2033-2046.

Kivircik Akdede BB, Alptekin K, Kitis A, Arkar H, Akvardar Y (2005). Effects of quetiapine on cognitive functions in schizophrenia. Prog Neuropsychopharmacol Biol Psychiatry 29: 233-238.

Koskinen T, Haapalinna A, Sirvio J (2003). Alpha-adrenoceptormediated modulation of 5-HT2 receptor afonist induced impulsive responding in a 5-choice serial reaction time task. Pharmacol Toxicol 92: 214-225.

Koskinen T, Sirvio J (2001). Studies on the involvement of the dopaminergic system in the 5HT2 agonist (DOI)-induced premature responding in a five-choice serial reaction time task. Brain Res Bull 54: 65-75.

Kuperberg G, Heckers S (2000). Schizophrenia and cognitive function. Curr Opin Neurobiol 10: 205-210.

Laurelle M (1998). Imaging dopamine transmission in schizophrenia. Quart J Nucl Sci 42: 211-221.

Laurelle M (1999). Dopamine as the wind of the psychotic fire: new evidence from brain imaging. J Psychopharmacol (Oxford) 14: 358-371.

Leyton M, Dagher A, Boileau I, Casey K, Baker GB, Diksic M et al (2004). Decreasing amphetamine-induced dopamine release by acute phenylalanine/tyrosine depletion: a PET/ raclopride study in healthy men. Neuropsychopharmacology 29: 427-432.

Leyton M, Young SN, Pihl RO, Etezadi S, Lauze C, Blier P et al (1999). A comparison of the effects of acute tryptophan depletion and acute phenylalanine/tyrosine depletion in healthy women. Adv Exp Med Biol 467: 67-71.

Leyton M, Young SN, Pihl RO, Etezadi S, Lauze C, Blier P, Baker GB, Benkelfat C (2000). Effects on mood of acute phenylalanine/ tyrosine depletion in healthy women. Neuropsychopharmacology 22: $52-63$.

Lucki I, Harvey JA (1976). Increased sensitivity to D- and Lamphetamine action after midbrain raphe lesions as measured by locomotor activity. Neuropharmacology 18: 243-249.

MacLeod CM (1991). Half a century of research on the Stroop effect: an integrative review. Psychol Bull 109: 163-203.

Matrenza C, Hughes J, Kemp AH, Wesnes KA, Harrison BJ, Nathan PJ (2004). Simultaneous depletion of serotonin and catecholamines impairs sustained attention in healthy female subjects without affecting learning and memory. J Psychopharmacol (Oxford) 18: 21-31.

McGowan S, Lawrence AD, Sales T, Quested D, Grasby PM (2004). Presynaptic dopaminergic dysfunction in schizophrenia: a positron emission tomographic $\left[{ }^{18} \mathrm{~F}\right]$ Fluorodopa study. Arch Gen Psychiatry 61: 134-142. 
McRae-Degueurce A, Dennis T, Leger L, Scatton B (1985). Regulation of noradrenergic neuronal activity in the rat locus coeruleus by serotonergic afferents. Physiol Psychol 13: 188-196.

McTavish SF, Cowen PJ, Sharp T (1999a). The effect of a tyrosinefree amino acid mixture on regional brain catecholamine synthesis and release. Psychopharmacology (Berlin) 141: 182-188.

McTavish SFB, Callado L, Cowen PJ, Sharp T (1999b). Comparison of the effects of a-methyl-p-tyrosine and a tyrosine-free amino acid load on extracellular noradrenaline in the rat hippocampus in vivo. J Psychopharmacol (Oxford) 13: 379-384.

McTavish SFB, CmPerhson MH, Harmer CJ, Clark L, Sharp T, Goodwin GM et al (2001a). Antidopaminergic effects of dietary tyrosine depletion in healthy subjects and patients with manic illness. Br J Psychiatry 179: 356-360.

McTavish SFB, Raumann B, Cowen PJ, Sharp T (2001b). Tyrosine depletion attenuates the behavioural stimulant effects of amphetamine and cocaine in rats. Eur J Pharmacol 424: 115-119.

Mehta MA, Gumaste D, Montgomery AJ, McTavish SF, Grasby PM (2005). The effects of acute tyrosine and phenylalanine depletion on spatial working memory and planning in healthy volunteers are predicted by changes in striatal dopamine levels. Psychopharmacology (Berlin) 26: 56-68.

Moja EA, Cipollo P, Castoldi D, Tofanetti O (1989). Dose-response decrease in plasma tryptophan and in brain tryptophan and serotonin after tryptophan-free amino acid mixtures in rats. Life Sci 44: 97-976.

Moja EA, Lucini V, Benedetti F, Lucca A (1996). Decrease in plasma phenylalanine and tyrosine after phenylalanine-tyrosine free amino acid solutions in man. Life Sci 58: 2389-2395.

Montgomery AJ, McTavish SF, Cowen PJ, Grasby PM (2003). Reduction in brain dopamine concentration with dietary tyrosine plus phenylalanine depletion: a raclopride PET study. Am J Psychiatry 10: 1887-1889.

Nathan PJ, Hughes J, McInerney B, Harrison BJ (2004). Simultaneous depletion of tryptophan, tyrosine and phenylalanine as an experimental method to probe brain monoamine function in humans. Int J Neuropsychopharmacol 7: 171-176.

Neumann J, Lohmann G, Derrfuss J, Yves von Cramon D (2005). Meta-analysis of functional imaging data using replicator dynamics. Hum Brain Mapp 25: 165-173.

Nishizawa S, Benkelfat C, Young SN, Leyton M, Mzengeza S, De Montigny C et al (1997). Differences between males and females in rates of serotonin synthesis in human brain. Proc Natl Acad Sci USA 94: 5308-5313.

Nordahl TE, Carter CS, Salo RE, Kraft L, Baldo J, Salamat S et al (2001). Anterior cingulate metabolism correlates with Stroop errors in paranoid schizophrenia patients. Neuropsychopharmacology 25: 139-148.

Oldendorf WH, Szabo J (1976). Amino acid assignment to one of three blood brain barrier amino acid carriers. Am J Physiol 230: 94-98.

Palmour RM, Ervin FR, Baker GB, Young SN (1998). An amino acid mixture deficient in phenylalanine and tyrosine reduces cerebrospinal fluid catecholamine metabolites and alcohol consumption in vervet monkeys. Psychopharmacology (Berlin) 13: 1-7.

Parsons LH, Justice JB (1993). Perfusate serotonin increases extracellular dopamine in the nucleus accumbens as measured by in vivo microdialysis. Brain Res 606: 195-199.

Passetti F, Levita L, Robbins TW (2003). Sulpiride alleviates the attentional impairments of rats with medial prefrontal cortex lesions. Behav Brain Res 138: 59-69.

Perlstein W, Carter CS, Barch DM, Baird J (1998). The Stroop task and attention deficits in schizophrenia: a critical evaluation of card and single-trial Stroop methodologies. Neuropsychology 12: 414-425.
Reilly JG, McTavish SF, Young AH (1997). Rapid depletion of plasma tryptophan: a review of studies and experimental methodology. J Psychopharmacol (Oxford) 11: 381-392.

Riedel WJ, Klaassen T, Schmitt JAJ (2002). Tryptophan, mood and cognition. Brain Behav Immun 16: 581-589.

Robbins T (1997). Arousal systems and attentional processes. Biol Psychol 45: 57-71.

Roberts A, De Salvia A, Wilkinson L, Collins P, Muir J, Everitt B et al (1994). 6-Hydroxydopamine lesions of the prefrontal cortex in monkeys enhance performance on an analog of the wisconsin card sort test: Possible interactions with subcortical dopamine. J Neurosci 14: 2531-2544.

Roesch-Ely D, Scheffel H, Weiland S, Schwaniger M, Hundemer H, Kolter T et al (2005). Differential dopaminergic modulation of executive control in healthy subjects. Psychopharmacology (Berlin) 178: 420-430.

Rowley B, Van F, Mortimore C, Connell J (1997). Effects of acute tryptophan depletion on tests of frontal and temporal lobe function. J Psychopharmacol (Oxford) 11: A60.

Schmitt JAJ, Jorissen B, Sobezak S, van Boxtel MPJ, Hogervorst E, Deutz NEP et al (2000). Tryptophan depletion impairs memory consolidation but improves focused attention in healthy young volunteers. J Psychopharmacol (Oxford) 14: 21-29.

Segal DS (1976). Differential effects of para-chlorophenylalanine on amphetamine-induced locomotion and stereotypy. Brain Res 116: $267-276$.

Sheehan BD, Tharyan P, McTavish SFB, Campling GM, Cowen PJ (1996). Use of a dietary manipulation to depletion plasma tyrosine and phenylalanine in healthy subjects. J Psychopharmacol (Oxford) 10: 231-234.

Sobczak S, Riedel WJ, Booij I, Hen Rot MA, Deutz NEP, Honig A (2002). Cognition following acute tryptophan depletion: difference between first degree-degree relatives of bipolar disorder patients and matched healthy control volunteers. Psychol Med 32: 503-515.

Soubrie P, Reisine TD, LGlowinski J (1984). Functional aspects of serotonin transmission in the basal ganglia: a review and an in vivo approach using the push-pull cannula technique. Neuroscience 13: 606-625.

Stroop JR (1935). Studies of interference in serial verbal reactions. J Exp Psychol 18: 643-662.

Taylor SF, Kornblum S, Tandon R (1996). Facilitation and interference of selective attention in schizophrenia. J Psychiatr Res 30: 251-259.

Tian Y, Easton MJ, Goudreau JL, Lookingland KJ, Moore KE (1993). Neurochemical evidence that 5-hydroxytryptaminergic neurons tonically inhibit noradrenergic neurons terminating in the hypothalamus. Brain Res 607: 215-221.

van Gaalen MM, Brueggeman RJ, Bronius PFC, Schoffelmeer ANM, Vanderschuren LJMJ (2006). Behavioural disinhibition requires dopamine receptor activation. Psychopharmacology (Berlin) 187: 73-82.

Williams JH, Wellman NA, Geaney DP, Cowen PJ, Feldon J, Rawlins JNP (1996). Haloperidol reduces stroop interference and increases negative priming in healthy people. Schizophr Res 18: 223 .

Williams WA, Shoaf SE, Hommer D, Rawlings R, Linnoila M (1999). Effects of acute Tryptophan depletion on plasma and Cerebrospinal fluid Tryptophan and 5-hydroxyindoleacetic acid in normal volunteers. J Neurochem 72: 1641-1647.

Wolf ME, Roth RH (1987). Dopamine autoreceptors. In: Creese I, Fraser CM (eds). Dopamine Receptors. Liss: New York. pp 45-96.

Young SN, Smith SE, Phil RO, Ervin FR (1985). Tryptophan depletion causes rapid lowering of mood in normal males. Psychopharmacology (Berlin) 87: 173-177. 